\title{
Effects of quitting cannabis on respiratory symptoms
}

\author{
Robert J. Hancox ${ }^{1}$, Hayden H. Shin ${ }^{1}$, Andrew R. Gray ${ }^{1}$, Richie Poulton ${ }^{2}$ and \\ Malcolm R. Sears ${ }^{3}$
}

\author{
Affiliations: \\ ${ }^{1}$ Dept of Preventive and Social Medicine, Dunedin School of Medicine, Dunedin, New Zealand. \\ ${ }^{2}$ Dept of Psychology, University of Otago, Dunedin, New Zealand. \\ ${ }^{3}$ Firestone Institute for Respiratory Health, Michael de Groote School of Medicine, McMaster University and \\ St Joseph's Healthcare, Hamilton, ON, Canada.
}

\section{Correspondence:}

Robert J. Hancox, Dept of Preventive and Social Medicine, Dunedin School of Medicine, P0 Box 913, Dunedin, New Zealand.

E-mail: bob.hancox@otago.ac.nz

ABSTRACT Smoking cannabis is associated with symptoms of bronchitis. Little is known about the persistence of symptoms after stopping cannabis use. We assessed associations between changes in cannabis use and respiratory symptoms in a population-based cohort of 1037 young adults.

Participants were asked about cannabis and tobacco use at ages 18, 21, 26, 32 and 38 years. Symptoms of morning cough, sputum production, wheeze, dyspnoea on exertion and asthma diagnoses were ascertained at the same ages. Frequent cannabis use was defined as $\geqslant 52$ occasions over the previous year. Associations between frequent cannabis use and respiratory symptoms were analysed using generalised estimating equations with adjustments for tobacco smoking, asthma, sex and age.

Frequent cannabis use was associated with morning cough (OR 1.97, $\mathrm{p}<0.001)$, sputum production (OR 2.31, $\mathrm{p}<0.001)$ and wheeze (OR 1.55, $\mathrm{p}<0.001)$. Reducing or quitting cannabis use was associated with reductions in the prevalence of cough, sputum and wheeze to levels similar to nonusers.

Frequent cannabis use is associated with symptoms of bronchitis in young adults. Reducing cannabis use often leads to a resolution of these symptoms.

@ERSpublications

Smoking cannabis causes symptoms of bronchitis but these symptoms improve after quitting or cutting down cannabis use http://ow.ly/JGL2q

Editorial comment in Eur Respir J 2015; 46: 1-4 [DOI: 10.1183/09031936.00034515]

This article has supplementary material available from erj.ersjournals.com

Received: Dec 132014 | Accepted after revision: Feb 20 2015 | First published online: April 022015

Support statement: The Dunedin Multidisciplinary Health and Development Research Unit is supported by the Health Research Council (New Zealand). Funding from UK Medical Research Council (grants G0100527 and MR/K00381X/1), US National Institute on Aging (AG032282), US National Institute of Mental Health (MH077874), US National Institute on Drug Abuse (P30 DA023026) and the Jacobs Foundation was used to collect data used in this report. H.H. Shin was funded by a scholarship from the New Zealand Asthma Foundation. M.R. Sears holds the AstraZeneca Chair in Respiratory Epidemiology, McMaster University. Funding information for this article has been deposited with FundRef.

Conflict of interest: Disclosures can be found alongside the online version of this article at erj.ersjournals.com

Copyright OERS 2015 


\section{Introduction}

Cannabis is the world's most commonly used illicit drug [1]. In New Zealand, cannabis use is almost as widespread as tobacco and about half of young adults admit to having used it in the previous year [2-4]. The long-term respiratory effects of smoking cannabis remain uncertain: although there are numerous case reports of bullous lung disease in very heavy cannabis users, there is little epidemiological evidence that cannabis smoking causes chronic lung disease [5-8].

The effects of smoking cannabis on respiratory symptoms are better documented: even moderate levels of cannabis use are associated with proximal airway inflammation [9-11] and symptoms of bronchitis [11-17]. These associations persist after adjusting for tobacco smoking and also occur in those who only smoke cannabis, indicating that cannabis can cause bronchitis independently of tobacco [14].

Although prolonged tobacco smoking can cause irreversible airway obstruction, the cessation of tobacco smoking often leads to the resolution of respiratory symptoms within months of quitting [18-20]. It is important to know whether quitting cannabis leads to a similar resolution of symptoms. Only one study has explored the impact of changes in cannabis use on respiratory symptoms [21]. That study found that symptoms of bronchitis improved after quitting either cannabis or tobacco use. However, there was only a small number of cannabis quitters in the cohort and these observations need to be confirmed in a larger population-based study.

We studied the effect of quitting cannabis use in the Dunedin Multidisciplinary Health and Development Study, a population-based birth cohort. A previous analysis of this study found that many cannabis users had symptoms of bronchitis at the age of 21 years [16]. Further follow-up of this cohort has been undertaken at the ages of 26, 32 and 38 years. We analysed associations between cannabis use and respiratory symptoms at these ages to assess whether symptoms of bronchitis persisted or resolved among those who continued or quit cannabis use.

\section{Methods}

The Dunedin Multidisciplinary Health and Development Study is a population-based birth cohort of 1037 people (52\% male) born in Dunedin between April 1972 and March 1973 [22, 23]. Participants have been followed throughout childhood and into adulthood. Follow-up rates have been high with $95 \%$ of the surviving cohort continuing to participate in the most recent assessment at age 38 years. The study is approved by the Otago Ethics Committee and written informed consent was obtained for each assessment.

Cannabis and tobacco smoking histories were obtained at the ages of 18, 21, 26, 32 and 38 years. At each assessment, participants were asked how many times they had used marijuana in the previous year. Frequent cannabis users are defined as those who reported using marijuana $\geqslant 52$ times (at least weekly on average) over the previous year. Those who used cannabis less than this were defined as infrequent or occasional users. Changes or persistence in frequent cannabis use between two consecutive assessments (e.g. between the ages of 21 and 26 or between 32 and 38 years) were used to classify study members as "nonusers" (not using cannabis frequently in either the current or previous assessment), "quitters" (frequent cannabis use at the previous assessment but less than frequent at the current assessment), "starters" (not using cannabis frequently at the previous assessment but using it frequently now) and "continuing users" (frequent cannabis use at both assessments). Cumulative cannabis use was measured in joint-years (one "joint" of cannabis a day for 1 year is defined as 1 joint-year), as previously reported [23]. For the purpose of calculating joint-years, if cannabis data were missing for one assessment, the amount of cannabis use reported at the previous assessment was used.

Current tobacco smoking is defined as smoking at least one cigarette a day for a month in the previous year [24]. Cumulative tobacco use was calculated in pack-years (20 cigarettes a day for 1 year is defined as 1 pack-year), as previously reported [23].

At each of these assessments, participants were asked if they had symptoms of cough, sputum production, wheeze and dyspnoea on exertion. Cough was defined as a positive answer to the question "Do you usually cough on getting up or first thing in the morning?". Sputum production was defined as a positive answer to the question "Do you usually bring up phlegm from your chest on getting up or first thing in the morning?". Current wheeze was defined as recurrent episodes of wheezing in the previous year, excluding those with only one or two episodes lasting $<1 \mathrm{~h}$, as previously reported [25]. Dyspnoea on exertion was defined as a positive answer to the question "Are you troubled by shortness of breath when hurrying on the level or walking up a slight hill?". Current asthma was defined as a self-reported diagnosis of asthma with episodes of asthma, wheezing or asthma medication use within the previous year. Height and weight were measured in light clothing without shoes at each assessment to calculate body mass index (BMI) in $\mathrm{kg} \cdot \mathrm{m}^{-2}$. 


\section{Statistical analysis}

Logistic regression analyses were used to assess the associations between both current frequent cannabis use at the age of 38 years and cumulative joint-years of cannabis use up to the age of 38 years with the symptoms of morning cough, sputum production, current wheeze and dyspnoea on exertion. These analyses were adjusted for both current (yes/no) and cumulative (pack-years) tobacco smoking, asthma diagnosis, and sex. Further analyses tested for potential interactions between tobacco and cannabis use by fitting a term for current smoking by frequent cannabis use in the models. To assess whether respiratory symptoms persisted after quitting frequent cannabis use, the logistic regression analyses were repeated using cumulative joint-years of cannabis exposure as the main predictor and excluding those reporting current frequent cannabis use at the age of 38 years.

The associations between frequent cannabis use and symptoms of morning cough, morning sputum production, current wheeze and dyspnoea on exertion at each assessment age were assessed using generalised estimating equations to take into account repeated measures among individuals, while adjusting for age, tobacco smoking, asthma diagnosis at that assessment and sex. Further analyses also tested for potential interactions between cannabis and tobacco as described above. Sensitivity analyses repeated the analyses among non-tobacco smokers and current tobacco smokers separately. Because both tobacco and cannabis smoking habits may influence body weight $[26,27]$, which may in turn influence respiratory symptoms [28], additional sensitivity analyses included BMI in the models and excluded pregnant women.

Generalised estimating equations were further used to assess the effect of changes in cannabis use between each assessment on the presence of respiratory symptom at the next assessment, with adjustments for the same covariates. Pairwise comparisons between categories were investigated where the overall test was statistically significant.

Finally, to assess whether quitting or reducing cannabis use was associated with improvements in morning cough, morning sputum production, current wheeze and dyspnoea on exertion, within-individual changes in these symptoms among those who quit or reduced their use to less than "frequently" were assessed by comparing the presence of these symptoms before and after quitting or cutting down. These were performed using McNemar's Chi-squared for matched pairs of binary data. Because it would be possible to "quit" frequent cannabis use more than once during the follow-up from 18 to 38 years of age, only the first recorded episode of quitting was used. Similarly, we assessed the persistence of symptoms among those who continued frequent use of cannabis using data from the first two consecutive phases in which continuing frequent cannabis use was recorded.

Analyses used all available data: the number of participants available for the analyses of each symptom varied slightly because of missing data for some symptoms. Statistical significance was defined as two-sided p-values $<0.05$. Analyses were performed using Stata (version 13; StataCorp, College Station, TX, USA).

\section{Results}

The prevalence of frequent and occasional cannabis use, changes and persistence in frequent cannabis use between each assessment, and the prevalence of morning cough, sputum production, wheeze and dyspnoea on exertion at each age are shown in table 1. Cannabis use was associated with tobacco: at each age, between $68 \%$ and $83 \%$ of frequent cannabis users were also current tobacco smokers $(p<0.001)$ (table S1).

Symptoms of morning cough, sputum production, wheeze, and dyspnoea on exertion at the age of 38 years were all significantly associated with both current cannabis use and cumulative cannabis use after adjustment for current and cumulative tobacco smoking, asthma and sex (table 2). After excluding current frequent cannabis users at the age of 38 years, morning cough and wheeze, but not sputum production or dyspnoea on exertion, were associated with cumulative cannabis use. An association between cumulative cannabis use and morning cough persisted if participants reporting any cannabis use in the past year were excluded (OR 1.18, $\mathrm{p}=0.014$ ). There were no significant interactions between current tobacco and cannabis use for any of the symptoms (all $\mathrm{p} \geqslant 0.062$ ).

Using generalised estimating equations adjusted for sex, age, and asthma and tobacco smoking at that age, it was found that morning cough, sputum production and wheeze were associated with frequent cannabis use (table 3). The association between cannabis use and dyspnoea was not quite statistically significant $(\mathrm{p}=0.086)$. There were no significant interactions between tobacco and cannabis use for any of the symptoms (all $\mathrm{p} \geqslant 0.317$ ) and the findings were similar among current tobacco smoking and nonsmoking subgroups (table S2). Including BMI as an additional covariate made no material difference to the analyses (table S3).

Changes in cannabis use between assessments were also associated with the prevalence of morning cough, sputum and wheeze (all $\mathrm{p} \leqslant 0.006)$, but not dyspnoea $(\mathrm{p}=0.347)$ (table 4$)$. For the three symptoms with statistically significant differences overall, those who had quit frequent cannabis use since the previous 
TABLE 1 Prevalence of cannabis use, tobacco smoking and respiratory symptoms at each assessment

\begin{tabular}{|c|c|c|c|c|c|}
\hline & \multicolumn{5}{|c|}{ Assessment age years } \\
\hline & 18 & 21 & 26 & 32 & 38 \\
\hline Cannabis use ${ }^{\#}$ & 934 & 956 & 976 & 968 & 948 \\
\hline Frequent & 81 (9) & $157(16)$ & $162(17)$ & $138(14)$ & $99(10)$ \\
\hline Occasional & $337(36)$ & 339 (35) & $327(34)$ & $222(23)$ & $146(15)$ \\
\hline Change in cannabis use ${ }^{\pi}$ & & 934 & 946 & 957 & 939 \\
\hline Nonuser & & $768(82)$ & $736(78)$ & $768(80)$ & 793 (84) \\
\hline Quitter & & $26(3)$ & $52(6)$ & $54(6)$ & $50(5)$ \\
\hline Starter & & $85(9)$ & $56(6)$ & $35(4)$ & $12(1)$ \\
\hline Continuing & & $55(6)$ & $102(11)$ & $100(10)$ & $84(9)$ \\
\hline Tobacco smoking & 868 & 946 & 969 & 972 & 957 \\
\hline Current & 284 (33) & 347 (37) & $352(36)$ & 343 (35) & $253(26)$ \\
\hline \multicolumn{6}{|l|}{ Symptoms } \\
\hline Cough & $120 / 868(14)$ & $125 / 946(13)$ & $176 / 972(18)$ & $165 / 968(17)$ & $132 / 947(14)$ \\
\hline Sputum & $108 / 868(12)$ & $132 / 946(14)$ & $170 / 972(17)$ & $142 / 966(15)$ & $91 / 946(10)$ \\
\hline Wheeze & $276 / 868$ (32) & $390 / 957(41)$ & $356 / 972$ (37) & $266 / 972$ (27) & $248 / 948(26)$ \\
\hline Dyspnoea & $206 / 868$ (24) & $320 / 946(24)$ & $219 / 970$ (23) & $177 / 962$ (18) & $190 / 946(20)$ \\
\hline
\end{tabular}

Data are presented as $n, n(\%)$ or $n / N(\%)$. Differences in $n$-values at each age and denominators for prevalences reflect missing data among active study participants. "\#: frequent cannabis use was defined as $\geqslant 52$ times in the previous year (weekly); occasional cannabis use was defined as between one and 51 occasions in the previous year. ": changes in cannabis use are changes in reported frequent use since the previous assessment.

assessment had a similar prevalence of these symptoms to those who had not been frequent cannabis users at either the preceding or current assessment (all $p \geqslant 0.321)$. By contrast, continuing frequent cannabis users had a higher prevalence of these symptoms (all $\mathrm{p} \leqslant 0.001$ ). Those who had started frequent cannabis use since the last assessment also had a higher prevalence of morning cough $(\mathrm{p}=0.034)$ and sputum $(p \leqslant 0.001)$ but not wheeze $(p=0.164)$. This pattern of findings was similar if current tobacco smokers and nonsmokers were analysed separately (tables S4). Those who quit were less likely to have morning cough or sputum compared to continuing users $(\mathrm{p}<0.001)$ but a lower prevalence of wheeze did not reach statistical significance $(\mathrm{p}=0.118)$.

Changes in the prevalence of morning cough, sputum production, wheeze and dyspnoea among those who continued or quit frequent cannabis smoking between assessments are shown in figure 1 . Over the assessment phases between ages 18 and 38 years, 161 participants who had been using cannabis frequently

\begin{tabular}{|c|c|c|c|c|}
\hline & Cannabis use & Participants n & OR $(95 \% \mathrm{CI})$ & p-value \\
\hline \multirow[t]{3}{*}{ Cough } & Current & 942 & $3.46(2.02-5.93)$ & $<0.001$ \\
\hline & Cumulative & 934 & $1.07(1.03-1.10)$ & $<0.001$ \\
\hline & Cumulative (excluding current frequent users) & 839 & $1.07(1.00-1.15)$ & 0.047 \\
\hline \multirow[t]{3}{*}{ Sputum } & Current & 942 & $3.45(1.96-6.11)$ & $<0.001$ \\
\hline & Cumulative & 934 & $1.04(1.01-1.08)$ & 0.017 \\
\hline & Cumulative (excluding current frequent users) & 839 & $0.92(0.81-1.05)$ & 0.220 \\
\hline \multirow[t]{3}{*}{ Wheeze } & Current & 943 & $1.95(1.11-3.42)$ & 0.020 \\
\hline & Cumulative & 935 & $1.05(1.02-1.09)$ & 0.002 \\
\hline & Cumulative (excluding current frequent users) & 840 & $1.09(1.02-1.17)$ & 0.008 \\
\hline \multirow[t]{3}{*}{ Dyspnoea } & Current & 941 & $1.73(1.00-2.99)$ & 0.048 \\
\hline & Cumulative & 933 & $1.04(1.00-1.07)$ & 0.031 \\
\hline & Cumulative (excluding current frequent users) & 838 & $1.04(0.98-1.12)$ & 0.214 \\
\hline
\end{tabular}

Analyses are adjusted for current and cumulative (pack-years) tobacco smoking, sex, body mass index, and asthma diagnosis. Odds ratios represent the odds associated with current frequent cannabis use compared to non- or infrequent use or with each additional joint-year of cumulative lifetime exposure. Differences between $\mathrm{n}$-values for current and cumulative use reflect missing data. 
TABLE 3 Associations between current cannabis use and respiratory symptoms across multiple assessments using generalised estimating equations

\begin{tabular}{lcccc} 
& Participants & Mean observations per participant & OR (95\% CI) & p-value \\
\hline Cough & 1000 & 4.7 & $1.97(1.57-2.48)$ & $<0.001$ \\
Sputum & 1000 & 4.7 & $2.31(1.83-2.91)$ & $<0.001$ \\
Wheeze & 998 & 4.7 & $1.55(1.23-1.94)$ & $<0.001$ \\
Dyspnoea & 1000 & 4.7 & $1.23(0.97-1.56)$ & 0.086
\end{tabular}

Analyses were adjusted for sex, age of assessment, and tobacco use and asthma at that age. Odds ratios represent the odds associated with current frequent cannabis use compared with non- or infrequent use.

either quit or reduced cannabis use to less than weekly for at least one assessment phase. Among these, 46 (29\%) reported a morning cough at the visit before they quit. This prevalence fell to $32(20 \%)$ at the assessment after quitting $(\mathrm{p}=0.031)$. The number reporting morning sputum production fell from 42 $(26 \%)$ at the assessment before quitting to $22(14 \%)$ after quitting $(p=0.001)$. The number reporting wheeze fell from $72(45 \%)$ at the assessment before quitting to $56(35 \%)$ after quitting $(\mathrm{p}=0.039)$. The prevalence of dyspnoea was similar before (27\%) and after (23\%) quitting ( $\mathrm{p}=0.355)$.

Only 50 participants who had used cannabis frequently quit completely between consecutive assessments (cannabis use reduced from $\geqslant 52$ times a year to none at all). Among these participants, the magnitude of changes in cough ( $30 \%$ to $20 \%, \mathrm{p}=0.096)$ and wheeze ( $40 \%$ to $30 \%, \mathrm{p}=0.225$ ) were similar to the reductions observed with reducing cannabis use from weekly to less than weekly. There was a greater fall in sputum production from $28 \%$ to $6 \%$ ( $\mathrm{p}=0.001$ ). Dyspnoea was unchanged ( $32 \%$ to $26 \%, \mathrm{p}=0.405$ )

Over the assessment phases between ages 18 and 38 years, 158 participants continued to use cannabis frequently for at least two consecutive phases. Between these assessments, the prevalence of cough increased from $30 \%$ ( 47 out of 158 subjects) to $44 \%$ ( 69 out of 158 subjects) ( $\mathrm{p}=0.002$ ) but there were no significant changes in the prevalence of sputum production ( $35 \%$ versus $39 \%$; $=0.297$ ), wheeze $(46 \%$ versus $46 \%, \mathrm{p}=1.00$ ) or dyspnoea on exertion ( $32 \%$ versus $31 \%, \mathrm{p}=0.882$ ).

\section{Discussion}

In this population-based cohort followed through early adulthood, the use of cannabis was associated with symptoms of cough, sputum production, wheeze and dyspnoea. These associations were independent of tobacco smoking and asthma. Symptoms of cough and sputum production tended to improve in those who stopped using cannabis frequently but persisted or worsened in those who continued to use cannabis

TABLE 4 Associations between changes in cannabis use between assessments and respiratory symptoms across multiple assessments using generalised estimating equations

\begin{tabular}{|c|c|c|c|c|c|}
\hline & Participants $n$ & Mean observations per participant & Group & OR $(95 \% \mathrm{CI})$ & p-value \\
\hline \multirow[t]{4}{*}{ Cough } & 985 & 3.8 & Nonuser & Ref. & $<0.001$ \\
\hline & & & Quitter & $1.17(0.79-1.74)$ & \\
\hline & & & Starter & $1.49(1.03-2.16)$ & \\
\hline & & & Continuing & $2.84(2.09-3.85)$ & \\
\hline \multirow[t]{4}{*}{ Sputum } & 985 & 3.8 & Nonuser & Ref. & $<0.001$ \\
\hline & & & Quitter & $0.91(0.59-1.43)$ & \\
\hline & & & Starter & $1.91(1.34-2.71)$ & \\
\hline & & & Continuing & $3.06(2.24-4.16)$ & \\
\hline \multirow[t]{4}{*}{ Wheeze } & 985 & 3.8 & Nonuser & Ref. & 0.006 \\
\hline & & & Quitter & $1.21(0.83-1.77)$ & \\
\hline & & & Starter & $1.29(0.90-1.84)$ & \\
\hline & & & Continuing & $1.72(1.27-2.34)$ & \\
\hline \multirow[t]{4}{*}{ Dyspnoea } & 985 & 3.8 & Nonuser & Ref. & 0.347 \\
\hline & & & Quitter & $1.14(0.78-1.67)$ & \\
\hline & & & Starter & $1.19(0.83-1.72)$ & \\
\hline & & & Continuing & $1.33(0.96-1.85)$ & \\
\hline
\end{tabular}

Analyses were adjusted for sex, age of assessment, and tobacco use and asthma at that age. Odds ratios represent the odds associated with changes in cannabis use compared with the reference (nonuser) group. 




FIGURE 1 Prevalence of symptoms before and after quitting regular cannabis use (open triangles) and among those who used cannabis regular for two consecutive phases (solid squares). Vertical bars show $95 \%$ confidence intervals.

frequently. These findings indicate that cannabis users have a high prevalence of bronchitis but that this often resolves on quitting.

Although all of the four respiratory symptoms were associated with both current and cumulative cannabis use at the age of 38 years, the symptoms most strongly associated with cannabis were cough and sputum production. These two symptoms also showed the greatest decline in prevalence among those who quit frequent use: across the assessments, those who had stopped using cannabis frequently did not have a higher prevalence of cough or sputum than nonusers, whereas starting frequent cannabis use was associated with an increase in these symptoms (table 4). By the age of 38 years, however, cumulative lifetime cannabis exposure was associated with morning cough and wheeze even after excluding current frequent cannabis users (table 2) and the association with cough at the age of 38 years persisted if those who had used any cannabis in the past year were excluded. These findings suggest that heavy cannabis use may sometimes lead to bronchitis symptoms that persist even after cutting down or quitting.

These findings confirm earlier reports that cannabis use is associated with a high prevalence of bronchitis symptoms [12-16], and extend the causal inference by demonstrating a temporal sequence between starting and quitting cannabis use and the development and resolution of symptoms. Although the majority of frequent cannabis users also smoked tobacco, the association of cough and sputum production with cannabis persisted after adjusting for tobacco use and also after excluding current tobacco users from the analyses, indicating that the association was unlikely to be due to confounding by tobacco use. The findings were also independent of asthma diagnosis, another potential confounder for symptoms of bronchitis in this age group.

We are aware of only one study that has explored the effect of stopping cannabis use on respiratory symptoms [21]. That study also found that quitting cannabis smoking was associated with a reduction in the symptoms of bronchitis among a cohort of adults aged 25-49 years, originally recruited from newspaper and radio announcements, who had been followed for a mean of 9.8 years. Unlike continuing smokers of either cannabis or tobacco, those who quit smoking either cannabis or tobacco during follow-up were no more likely to have chronic respiratory symptoms at follow up than never smokers.

Although the airways were not directly observed in this study, the finding that the prevalence of cough, sputum production and wheeze reduce to levels similar to non-cannabis users after quitting cannabis frequently suggests that the airway inflammation and bronchitis induced by cannabis are largely reversible. The extent to which bronchitis improves on quitting cannabis may be underestimated by this analysis because we classified those who had reduced their cannabis use to less than once a week as "quitters". Quitting cannabis use altogether appeared to have a greater effect on sputum production than reducing use: only $6 \%$ of frequent users who quit completely reported this symptom at follow-up.

These findings may provide an incentive for patients to consider quitting cannabis smoking. Surprisingly, major international guidelines do not mention cannabis smoking as a potential cause of cough [29-32]. It is not known how many patients presenting to health services with chronic cough are cannabis users, but the finding that cough and sputum production are so common among cannabis smokers suggests that this should be considered [33]. We do not know whether any of the participants in this study quit because of respiratory symptoms but our data suggest that quitting cannabis use may be one of the most effective management options for cough and sputum production. Unless clinicians specifically ask about cannabis 
use, this potential cause of the patient's symptoms may be missed because patients may be reluctant to volunteer information about illegal drug use.

A potential source of error in this study is the reliance on self-reports of cannabis use without objective confirmation. However, the study's well-established record of confidentiality and nonintervention tends to encourage reporting of use, and is likely to have minimised reporting bias. We also classified those who reported using cannabis $<52$ times a year as nonusers based on our assumption that infrequent cannabis use would be unlikely to have a major effect on respiratory symptoms. Hence, a modest reduction in reported cannabis use could have led to some study members being classified as quitters. Another limitation is that we asked about marijuana use but not specifically about smoking, although smoking marijuana is by far the most common method of using cannabis in New Zealand. However, such classification errors regarding the extent of cannabis smoking and quitting would be most likely to attenuate the observed associations with respiratory symptoms. The study has a number of important strengths, including the high cohort retention rate, and repeated measures of cannabis use, respiratory symptoms and potential confounding factors using standardised questionnaires.

In summary, frequent cannabis use is associated with symptoms of cough, sputum production and wheeze independently of tobacco smoking. These symptoms tend to improve in people who quit indicating that the airway inflammation caused by cannabis may be largely reversible.

\section{Acknowledgements}

We thank the study members their friends and families for their continued support. We also thank Phil Silva, the study founder, and the unit staff. We are grateful to Terrie Moffit and Avshalom Caspi (Duke University, Durham, NC, USA) for sharing data used in this report.

\section{References}

$1 \quad$ United Nations Office on Drugs and Crime. World Drug Report. Vienna, United Nations, 2013.

2 Ministry of Health. Drug use in New Zealand: key results of the 2007/08 New Zealand Alcohol and drug use survey. Wellington, Ministry of Health, 2010.

3 Poulton RG, Brooke M, Moffitt TE, et al. Prevalence and correlates of cannabis use and dependence in young New Zealanders. NZ Med J 1997; 110: 68-70.

4 Poulton $\mathrm{R}$, Moffitt TE, Harrington $\mathrm{H}$, et al. Persistence and perceived consequences of cannabis use and dependence among young adults: implications for policy. NZ Med J 2001; 114: 544-547.

5 Johnson MK, Smith RP, Morrison D, et al. Large lung bullae in marijuana smokers. Thorax 2000; 55: 340-342. Hii SW, Tam JD, Thompson BR, et al. Bullous lung disease due to marijuana. Respirology 2008; 13: 122-127.

Lee MH, Hancox RJ. Effects of smoking cannabis on lung function. Expert Rev Respir Med 2011; 5: 537-547. Joshi M, Joshi A, Bartter T. Marijuana and lung diseases. Curr Opin Pulm Med 2014; 20: 173-179.

Gong H, Fligiel S, Tashkin DP, et al. Tracheobronchial changes in habitual, heavy smokers of marijuana with and without tobacco. Am Rev Respir Dis 1987; 136: 142-149.

10 Fligiel SE, Roth MD, Kleerup EC, et al. Tracheobronchial histopathology in habitual smokers of cocaine, marijuana, and/or tobacco. Chest 1997; 112: 319-326.

11 Roth MD, Arora A, Barsky SH, et al. Airway inflammation in young marijuana and tobacco smokers. Am J Respir Crit Care Med 1998; 157: 928-937.

12 Bloom JW, Kaltenborn WT, Paoletti P, et al. Respiratory effects of non-tobacco cigarettes. Br Med J (Clin Res Ed) 1987; 295: 1516-1518.

13 Tashkin DP, Coulson AH, Clark VA, et al. Respiratory symptoms and lung function in habitual heavy smokers of marijuana alone, smokers of marijuana and tobacco, smokers of tobacco alone, and nonsmokers. Am Rev Respir Dis 1987; 135: 209-216.

14 Moore BA, Augustson EM, Moser RP, et al. Respiratory Effects of Marijuana and Tobacco Use in a U.S. Sample. J Gen Intern Med 2005; 20: 33-37.

15 Sherrill DL, Krzyzanowski M, Bloom JW, et al. Respiratory effects of non-tobacco cigarettes: a longitudinal study in general population. Int J Epidemiol 1991; 20: 132-137.

16 Taylor DR, Poulton R, Moffitt TE, et al. The respiratory effects of cannabis dependence in young adults. Addiction 2000; 95: 1669-1677.

17 Tetrault JM, Crothers K, Moore BA, et al. Effects of Marijuana smoking on pulmonary function and respiratory complications: a systematic review. Arch Intern Med 2007; 167: 221-228.

18 Krzyzanowski M, Robbins DR, Lebowitz MD. Smoking cessation and changes in respiratory symptoms in two populations followed for 13 years. Int J Epidemiol 1993; 22: 666-673.

19 Kanner RE, Connett JE, Williams DE, et al. Effects of randomized assignment to a smoking cessation intervention and changes in smoking habits on respiratory symptoms in smokers with early chronic obstructive pulmonary disease: the Lung Health Study. Am J Med 1999; 106: 410-416.

20 Etter JF. Short-term change in self-reported COPD symptoms after smoking cessation in an internet sample. Eur Respir J 2010; 35: 1249-1255.

21 Tashkin DP, Simmons MS, Tseng CH. Impact of changes in regular use of marijuana and/or tobacco on chronic bronchitis. COPD 2012; 9: 367-374.

22 Silva PA, Stanton WR. From child to adult: the Dunedin Multidisciplinary Health and Development Study. Auckland, Oxford University Press, 1996.

23 Hancox RJ, Poulton R, Ely M, et al. Effects of cannabis on lung function: a population-based cohort study. Eur Respir J 2010; 35: 42-47. 
24 Ferris BG. Epidemiology standardization project (American Thoracic Society). Am Rev Respir Dis 1978; 118: $1-120$.

25 Hancox RJ, Milne BJ, Poulton R, et al. Sex differences in the relation between body mass index and asthma and atopy in a birth cohort. Am J Respir Crit Care Med 2005; 171: 440-445.

26 Robertson L, McGee R, Hancox RJ. Smoking cessation and subsequent weight change. Nicotine Tob Res 2014.

27 Le Strat Y, Le Foll B. Obesity and cannabis use: results from 2 representative national surveys. Am J Epidemiol 2011; 174: 929-933.

28 Rasmussen F, Hancox RJ. Mechanisms of obesity in asthma. Curr Opin Allergy Clin Immunol 2014; 14: 35-43.

29 Morice AH, Fontana GA, Sovijarvi ARA, et al. The diagnosis and management of chronic cough. Eur Respir J 2004; 24: 481-492.

30 Morice AH, McGarvey L, Pavord I, et al. Recommendations for the management of cough in adults. Thorax 2006; 61: i1-i24.

31 Pratter MR. Overview of common causes of chronic cough: ACCP evidence-based clinical practice guidelines. Chest 2006; 129: 59S-62S.

32 Gibson PG, Chang AB, Glasgow NJ, et al. CICADA: cough in children and adults: diagnosis and assessment. Australian cough guidelines summary statement. Med J Aust 2010; 192: 265-271.

33 Davis GP, Gunderson EW. Evaluation of chronic cough should consider cannabis use. Am Fam Physician 2012; 85: 680 . 